\title{
ANALYSIS OF MHD TRANSIENT FREE CONVECTION FLOW OF A NEWTONIAN FLUID PAST AN INFINITE VERTICAL POROUS PLATE
}

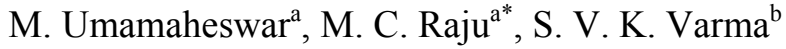 \\ ${ }^{a}$ Department of Humanities and Sciences, Annamacharya Institute of Technology and Sciences Rajampet (Autonomous), Rajampet, Andhra Pradesh, \\ 516126 India \\ ${ }^{b}$ Department of Mathematics, S. V. University, Tirupati, 517502, Andhra Pradesh, India
}

\begin{abstract}
An investigation is carried out to analyze the unsteady MHD free convection, heat and mass transfer flow of a Newtonian fluid past an infinite vertical porous plate with homogeneous chemical reaction and heat absorption/generation. A uniform magnetic field is applied perpendicular to the plate. The non-dimensional governing equations are solved numerically by using finite difference method. The effects of various parameters governing the flow on velocity, temperature, concentration, skin friction, Nusselt number and Sherwood number are studied through graphs. It is noticed that velocity decreases with an increase in Magnetic field while it increases with an increase in Grashof number, modified Grashof number\& Permeability parameter. Temperature increases with an increase in heat absorption and it shows reverse effect in the case of heat generation and Prandtl number. Concentration decreases with increase in Schmidt number and chemical reaction parameter.
\end{abstract}

Keywords: MHD, Free convection, Porous medium, Vertical plate, Newtonian fluid, Finite difference Method and Chemical reaction.

\section{INTRODUCTION}

In recent years, the analysis of hydro magnetic convection flow involving heat and mass transfer in porous medium has attracted the attention of many scholars because of its possible applications in diverse fields of science and technology such as soil sciences, astrophysics, Geophysics, nuclear power reactors etc. Magneto hydrodynamic free convection flow of an electrically conducting fluid in different porous geometries is of considerable interest to the technical field due to its frequent occurrence in industrial, technological and geothermal applications. As an example, the geothermal region gases are electrically conducting and undergo the influence of magnetic field. Also, it has applications in nuclear engineering in connection with reactors cooling. The interest in this field is due to the wide range of applications in engineering and geophysics, such as the optimization of the solidification processes of metals and metal alloys, the study of geothermal sources, the treatment of nuclear fuel debris, the control of underground spreading of chemical wastes and pollutants and the design of MHD power generators. Many papers concerned with the problem of MHD free convection flow in porous media have been published in the literature.

Chamkha (2003) studied MHD flow of a uniformly stretched vertical permeable surface in the presence of heat generation/absorption and a chemical reaction. Kim (2000) analyzed unsteady MHD convective heat transfer past a semi-infinite vertical porous moving plate with variable suction. Chamkha (2004) has studied unsteady MHD convective heat and mass transfer past a semi-infinite vertical permeable moving plate with heat absorption. Pal (2013) analyzed Hall current and MHD effects on heat transfer over an unsteady stretching permeable surface with thermal radiation. Cortell (2007) investigated MHD flow and mass transfer of an electrically conducting fluid of second grade in a porous medium over a stretching sheet with chemically reactive species.
On the other hand, Seth et al. (2011) analyzed MHD natural convection flow with radiative heat transfer past an Impulsively Moving Plate with ramped wall temperature. Muthucumaraswamy and Janakiraman (2006) studied MHD and radiation effects on moving isothermal vertical plate with variable mass diffusion. Umamaheswar et al. (2013) studied Unsteady MHD free convective visco-elastic fluid flow bounded by an infinite inclined porous plate in the presence of heat source, viscous dissipation and ohmic heating. Singh (2001) has studied MHD free convection and mass transfer flow with heat source and thermal diffusion. Mishra et al. (2013) analyzed Mass and heat transfer effect on MHD flow of a visco-elastic fluid through porous medium with oscillatory suction and heat source. Vajravelu et al. (2013) studied unsteady convective boundary layer flow of a viscous fluid at a vertical surface with variable fluid properties. Hayat et al. (2011) studied MHD flow and heat transfers over permeable stretching sheet with slip conditions. Pal and Chatterjee (2010) analyzed Heat and Mass Transfer in MHD Non-Darcian Flow of a Micro polar Fluid over a Stretching Sheet Embedded in a Porous Media with Non-Uniform Heat Source and Thermal Radiation.

Muthucumaraswamy and Ganesan (2002) studied natural convection on a moving isothermal vertical plate with chemical reaction. Patil et al. (2013) analyzed Chemical Reaction Effects on Unsteady Mixed Convection Boundary Layer Flow Past a Permeable Slender Vertical Cylinder Due to a Nonlinearly Stretching Velocity. Kandasamy et al. (2005) studied Chemical reaction, heat and mass transfer on MHD flow over a vertical stretching surface with heat source and thermal stratification effects. Takhar et al. (2000) studied flow and mass transfer on a stretching sheet with a magnetic field and chemically reactive species. Raptis and Perdikis (2006) studied viscous flow over a non-linearly stretching sheet in the presence of a chemical reaction and magnetic field. Kandasamy et al. (2010) analyzed Lie group analysis for the effect of temperature dependent fluid viscosity with thermophoresis and chemical reaction on MHD free convective heat and mass transfer over a porous stretching surface in the presence

* Corresponding author email: mcrmaths@yahoo.co.in, umasvu8@gmail.com 
of heat source / sink. Anjalidevi and Kandasamy (2000) studied effects of a chemical reaction heat and mass transfer on MHD flow past a semi-infinite plate. Sonth et al. (2002) analyzed heat and mass transfer in a visco-elastic fluid flow over an accelerating surface with heat source/sink and viscous dissipation. Hossain and Mandal (1985) investigated mass transfer effects on the unsteady hydromagnetic free convection flow past an accelerated vertical porous plate. Khan et al. (2014) studied MHD boundary layer flow of a nanofluid containing gyro tactic microorganisms past a vertical plate with Navier slip. Seini and Makinde (2014) studied boundary layer flow near stagnation-points on a vertical surface with slip in the presence of transverse magnetic field. Jha, (1991) investigated MHD free convection mass transform flow through a porous medium. Prakash et al. (2013) studied diffusionthermo and radiation effects on unsteady MHD flow through porous medium past an impulsively started infinite vertical plate with variable temperature and mass diffusion. Seth and Ansari (2010) analyzed MHD natural convection flow past an impulsively Moving vertical plate with ramped wall temperature in the presence of thermal diffusion with heat absorption. Seth et al. (2013) studied effects of thermal radiation and rotation on unsteady hydromagnetic free convection flow past an impulsively moving vertical plate with ramped temperature in a porous medium. Seth et al. (2014a) analyzed hydromagnetic natural convection flow with radiative heat transfer past an accelerated moving vertical plate with ramped temperature through a porous medium. Seth et al. (2014c) considered Hall effects on unsteady MHD natural convection flow of a heat absorbing fluid past an accelerated moving vertical plate with ramped temperature. Seth et al. (2014b) investigated effects of Hall current and rotation on unsteady MHD natural convection flow with heat and mass transfer past an impulsively moving vertical plate in the presence of radiation and chemical reaction.

Based on the above studies we have considered the unsteady MHD free convection, heat and mass transfer flow of a Newtonian fluid past an infinite vertical porous plate with homogeneous chemical reaction and heat absorption/generation. We have extended the work of Kaprawi (2015) with the novelty of considering heat source, chemical reaction, porous permeability, magnetic field parameter and mass transfer.

\section{FORMULATION OF THE PROBLEM:}

We consider a viscous incompressible, electrically conducting, heat absorbing/generating and chemically reacting Newtonian fluid flow past an infinite vertical porous. A magnetic field of uniform strength is applied perpendicular to the plate. Let $\mathrm{x}^{*}$-axis is taken along the plate in the vertically upward direction and the $\mathrm{y}^{*}$-axis is taken perpendicular to the plate. At time $t \leq 0$, the plate is maintained at the temperature higher than ambient temperature $\mathrm{T}_{\infty}$ and the fluid is at rest. At time $t>0$, the plate is linearly accelerated with increasing time in its own plane and the temperature decreases with temperature $T=1 /(1+a t)$. Similarly the species concentration decreases with time $t$. It is assumed that the effect of viscous dissipation is negligible. By usual Boussineq's and boundary layer approximation, the unsteady flow is governed by the following equations:

$$
\begin{aligned}
& \frac{\partial \mathrm{u}^{*}}{\partial \mathrm{t}^{*}}=v \frac{\partial^{2} \mathrm{u}^{*}}{\partial \mathrm{y}^{*}}+\mathrm{g} \beta_{\mathrm{T}}\left(\mathrm{T}^{*}-\mathrm{T}_{\infty}\right)+\mathrm{g} \beta_{\mathrm{C}}\left(\mathrm{C}^{*}-\mathrm{C}_{\infty}\right)-\frac{\sigma \mathrm{B}_{0}^{2} \mathrm{u}^{*}}{\rho}-\frac{v}{\mathrm{k}} \mathrm{u}^{*}(1) \\
& \rho \mathrm{C}_{p} \frac{\partial \mathrm{T}^{*}}{\partial \mathrm{t}^{*}}=k_{T} \frac{\partial^{2} \mathrm{~T}^{*}}{\partial \mathrm{y}^{* 2}}-\mathrm{Q}^{*}\left(T^{*}-\mathrm{T}_{\infty}\right) \\
& \frac{\partial \mathrm{C}^{*}}{\partial \mathrm{t}^{*}}=\mathrm{D} \frac{\partial^{2} \mathrm{C}^{*}}{\partial \mathrm{y}^{* 2}}-\mathrm{K}_{\mathrm{r}}^{*}\left(\mathrm{C}^{*}-\mathrm{C}_{\infty}\right)
\end{aligned}
$$

The corresponding initial and boundary conditions are

$$
\left.\begin{array}{l}
u^{*}=0, T^{*}=T_{\infty}, \mathrm{C}^{*}=C_{\infty} \quad \text { for all } y^{*}, t^{*} \leq 0 \\
t^{*}>0: u^{*}=U_{0} a^{*} t^{*}, \mathrm{~T}^{*}=T_{\infty}+\left(\frac{T_{S}^{*}-T_{\infty}}{1+A t^{*}}\right), \\
\mathrm{C}^{*}=C_{\infty}+\left(\frac{C_{S}^{*}-C_{\infty}}{1+A t^{*}}\right) \text { at } y^{*}=0 \\
u^{*} \rightarrow 0, T^{*} \rightarrow T_{\infty}, \mathrm{C}^{*} \rightarrow C_{\infty} \quad \text { as } y^{*} \rightarrow \infty
\end{array}\right\}
$$

where $\mathrm{A}=\frac{\mathrm{U}_{0}^{2}}{v}$

The non-dimensional quantities are as follows:

$u=\frac{u^{*}}{U_{0}}, t=\frac{t^{*} U_{0}^{2}}{v}, y=\frac{y^{*} U_{0}}{v}, \theta=\frac{T^{*}-T_{\infty}}{T_{S}^{*}-T_{\infty}}, \mathrm{C}=\frac{C^{*}-C_{\infty}}{C_{S}^{*}-C_{\infty}}$,

$\mathrm{Gr}=\frac{v \mathrm{~g} \beta_{\mathrm{T}}\left(\mathrm{T}_{\mathrm{S}}^{*}-\mathrm{T}_{\infty}\right)}{\mathrm{U}_{0}^{3}}$, (Grashof number)

$G m=\frac{v g \beta_{C}\left(C_{S}^{*}-C_{\infty}\right)}{U_{0}^{3}}$, (Modified Grashof number)

$\mathrm{M}=\frac{\sigma \mathrm{B}_{0}^{2} v}{\rho \mathrm{U}_{0}^{2}}$, (Magnetic parameter)

$K=\frac{k U_{0}^{2}}{v^{2}}$, (Porous permeability)

$\operatorname{Pr}=\frac{\rho v \mathrm{C}_{\mathrm{p}}}{\mathrm{k}_{\mathrm{T}}}$, (Prandtl number)

$Q=\frac{Q^{*} v^{2}}{k_{T} U_{0}^{2}},($ Heat Source/Sink $)$

$\mathrm{Sc}=\frac{v}{\mathrm{D}},($ Schmidt number $)$

$K r=\frac{K_{r}^{*} v}{U_{0}^{2}}$, (Chemical reaction parameter)

After introducing the non-dimensional quantities into the equations (1)(3), these equations reduces to

$$
\begin{aligned}
& \frac{\partial \mathrm{u}}{\partial \mathrm{t}}=\frac{\partial^{2} \mathrm{u}}{\partial \mathrm{y}^{2}}+\mathrm{Gr} \theta+\mathrm{GmC}-\mathrm{Mu}-\frac{1}{\mathrm{~K}} \mathrm{u} \\
& \frac{\partial \theta}{\partial t}=\frac{1}{\operatorname{Pr}} \frac{\partial^{2} \theta}{\partial y^{2}}-\frac{Q}{\operatorname{Pr}} \theta \\
& \frac{\partial \mathrm{C}}{\partial \mathrm{t}}=\frac{1}{\mathrm{Sc}} \frac{\partial^{2} \mathrm{C}}{\partial \mathrm{y}^{2}}-\mathrm{KrC}
\end{aligned}
$$

The corresponding initial and boundary conditions are

$$
\left.\begin{array}{rr}
u=0, \theta=0, \mathrm{C}=0 \quad \text { for all } \mathrm{y}, \mathrm{t} \leq 0 \\
t>0: u=a t, \theta=\frac{1}{1+t}, \mathrm{C}==\frac{1}{1+t} & \text { at } y=0 \\
u \rightarrow 0, \theta \rightarrow 0, \mathrm{C} \rightarrow 0 & \text { as } y \rightarrow \infty
\end{array}\right\}
$$




\section{METHOD OF SOLUTION}

Equations (5)-(7) are linear partial differential equations and are to be solved by using the initial and boundary conditions (8). However exact solution is not possible for this set of equations and hence we solve these equations by finite-difference method. The equivalent finite difference schemes of equations for (5)-(7) are as follows:

$$
\begin{aligned}
& \frac{\mathrm{u}_{\mathrm{i}, \mathrm{j}+1}-\mathrm{u}_{\mathrm{i}, \mathrm{j}}}{\Delta \mathrm{t}}=\operatorname{Gr} \theta_{\mathrm{i}, \mathrm{j}}+\mathrm{GmC}_{\mathrm{i}, \mathrm{j}} \\
& +\frac{\mathrm{u}_{\mathrm{i}-1, \mathrm{j}}-2 \mathrm{u}_{\mathrm{i}, \mathrm{j}}+\mathrm{u}_{\mathrm{i}+1, \mathrm{j}}}{(\Delta \mathrm{y})^{2}}-\mathrm{Mu}_{\mathrm{i}, \mathrm{j}}-\frac{1}{\mathrm{~K}} \mathrm{u}_{\mathrm{i}, \mathrm{j}} \\
& \frac{\theta_{\mathrm{i}, \mathrm{j}+1}-\theta_{\mathrm{i}, \mathrm{j}}}{\Delta t}=\frac{1}{\operatorname{Pr}} \frac{\theta_{\mathrm{i}-1, j}-2 \theta_{i, j}+\theta_{i+1, j}}{(\Delta y)^{2}}-\frac{Q}{\operatorname{Pr}} \theta_{i, j} \\
& \frac{\mathrm{C}_{\mathrm{i}, \mathrm{j}+1}-\mathrm{C}_{\mathrm{i}, \mathrm{j}}}{\Delta \mathrm{t}}=\frac{1}{\mathrm{Sc}} \frac{\mathrm{C}_{\mathrm{i}-1, \mathrm{j}}-2 \mathrm{C}_{\mathrm{i}, \mathrm{j}}+\mathrm{C}_{\mathrm{i}+1, \mathrm{j}}}{(\Delta \mathrm{y})^{2}}-\mathrm{KrC}_{\mathrm{i}, \mathrm{j}}
\end{aligned}
$$

Here, the suffix $\mathrm{i}$ refer to $\mathrm{y}$ and $\mathrm{j}$ to time. The mesh system is divided by taking $\Delta y=0.1$. From the initial condition in (8), we have the following equivalent:

$$
u(i, 0)=0, \theta(i, 0)=0, C(i, 0)=0 \text { for all } i
$$

The boundary conditions from (8) are expressed in finite-difference form as follows

$$
\begin{aligned}
& \mathrm{u}(0, \mathrm{j})=\text { at, } \theta(0, \mathrm{j})=\frac{1}{1+\mathrm{t}}, \mathrm{C}(0, \mathrm{j})=\frac{1}{1+\mathrm{t}} \text { for all } \mathrm{j} \\
& \mathrm{u}\left(\mathrm{i}_{\max }, \mathrm{j}\right)=0, \theta\left(\mathrm{i}_{\max }, \mathrm{j}\right)=0, \mathrm{C}\left(\mathrm{i}_{\max }, \mathrm{j}\right)=0 \text { for all } \mathrm{j}
\end{aligned}
$$

(Here $i_{\max }$ was taken as 200)

First the velocity at the end of time step viz, $u(i, j+1)(i=1,200)$ is computed from (9) in terms of velocity, temperature and concentration at points on the earlier time-step. Then $\theta(i, j+1)$ is computed from (10) and $\mathrm{C}(\mathrm{i}, \mathrm{j}+1)$ is computed from $(11)$. The procedure is repeated until $\mathrm{t}=0.5$ (i.e. $\mathrm{j}=500$ ). During computation $\Delta \mathrm{t}$ was chosen as 0.001 .

\section{Skin-friction:}

The skin-friction in non-dimensional form is given by

$$
\tau=-\left(\frac{d u}{d y}\right)_{y=0}, \text { where } \tau=\frac{\tau^{1}}{\rho U_{0}^{2}}
$$

\section{Rate of heat transfer:}

The dimensionless rate of heat transfer is given by

$$
\mathrm{Nu}=-\left(\frac{\mathrm{d} \theta}{\mathrm{dy}}\right)_{\mathrm{y}=0}
$$

\section{Rate of mass transfer:}

The dimensionless rate of mass transfer is given by

$$
\mathrm{Sh}=-\left(\frac{\mathrm{dC}}{\mathrm{dy}}\right)_{\mathrm{y}=0}
$$

\section{RESULT AND DISCUSSION:}

The effects of various physical parameters viz., the Schmidt number $(\mathrm{Sc})$, the thermal Grashof number (Gr), the modified Grashof number $(\mathrm{Gm})$, magnetic parameter (M),Prandtl number (Pr) and chemical reaction parameter $(\mathrm{Kr})$ are exhibited in the figures $1-15$ and studied by choosing arbitrary values.

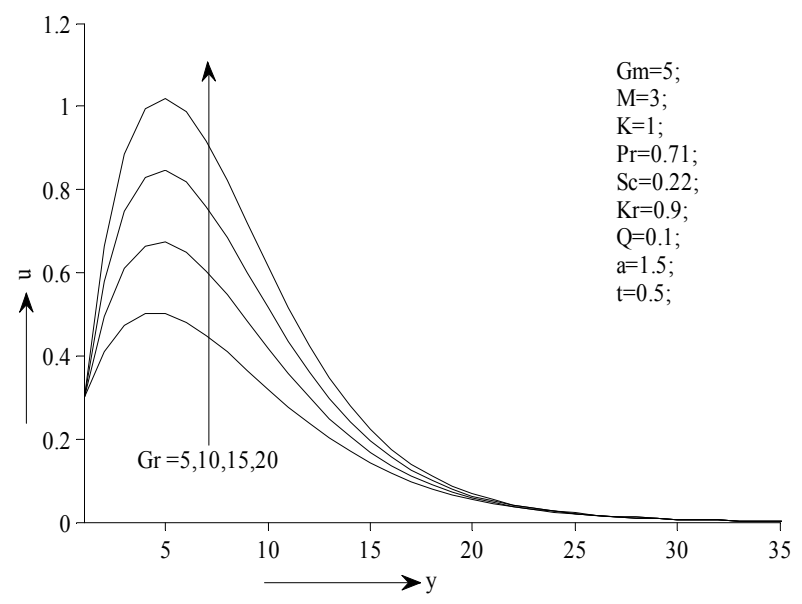

Fig. 1 Effect of Grashof number on velocity

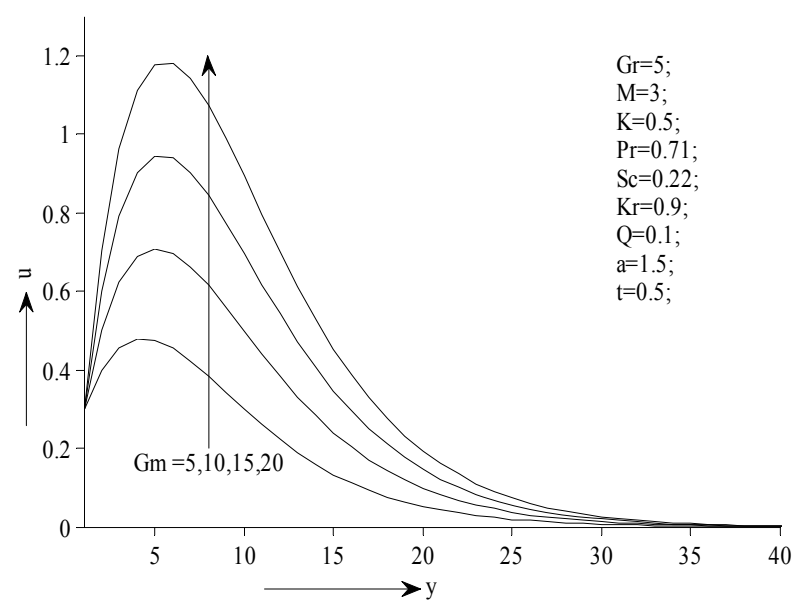

Fig. 2 Effect of Modified Grashof number on velocity

In Fig.1, effect of thermal Grashof number on velocity is presented. As Gr increases, velocity also increases. This is due to the buoyancy which is acting on the fluid particles due to gravitational force that enhances the fluid velocity. A similar effect is noticed from Fig.2, in the presence of modified Grashof number, which also increases fluid velocity. In figure 3, velocity profiles are displayed with the variation in magnetic parameter. From this figure it is noticed that velocity gets reduced by the increase of magnetic parameter. When an electrically conducting fluid moves in the presence of an applied magnetic field, a magnetic force, called Lorentz force, is generated in the flow field whose tendency is to resist the fluid motion. Due to this reason fluid velocity is getting retarded on increasing magnetic parameter $(M)$. Fig.4 depicts the variations in velocity profiles for different values of Permeability parameter. From this figure it is noticed that, velocity increases as $\mathrm{K}$ increases. Fig.5 indicates that a rise in $\mathrm{Pr}$ substantially reduces the temperature in the viscous fluid. It can be found from Fig. 5 that the thickness of thermal boundary layer decreases on increasing Pr. Fig.6 depicts the effect of heat absorption on temperature. It is noticed that the temperature decreases as an increase in the heat absorption parameter. 


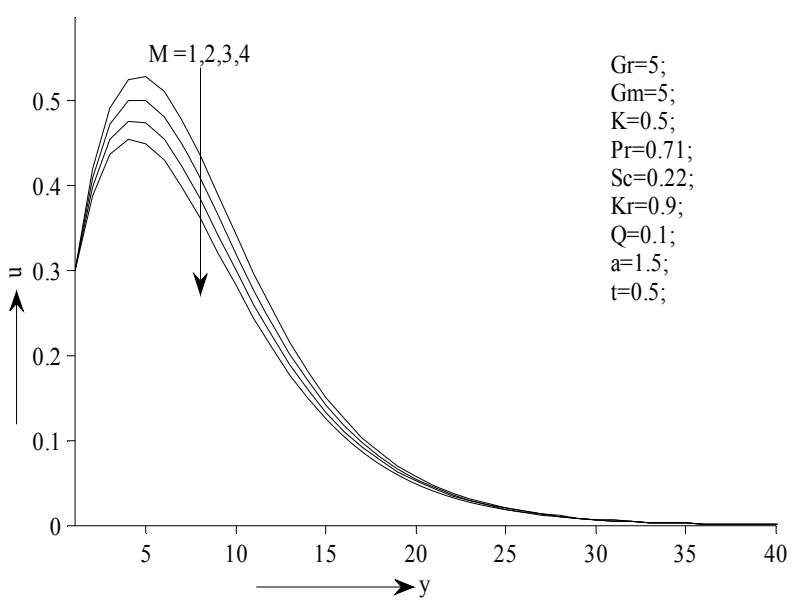

Fig. 3 Effect of Magnetic parameter (M) on velocity

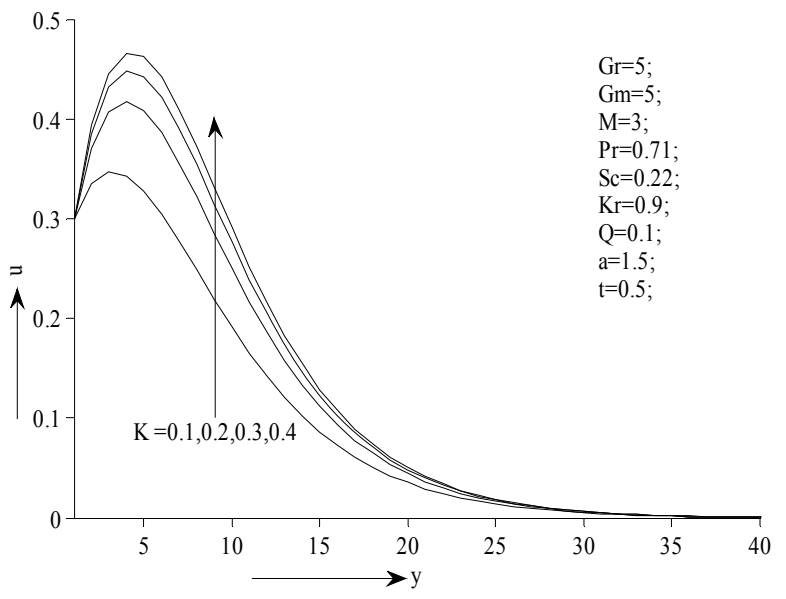

Fig. 4 Effect of Permeability parameter on velocity

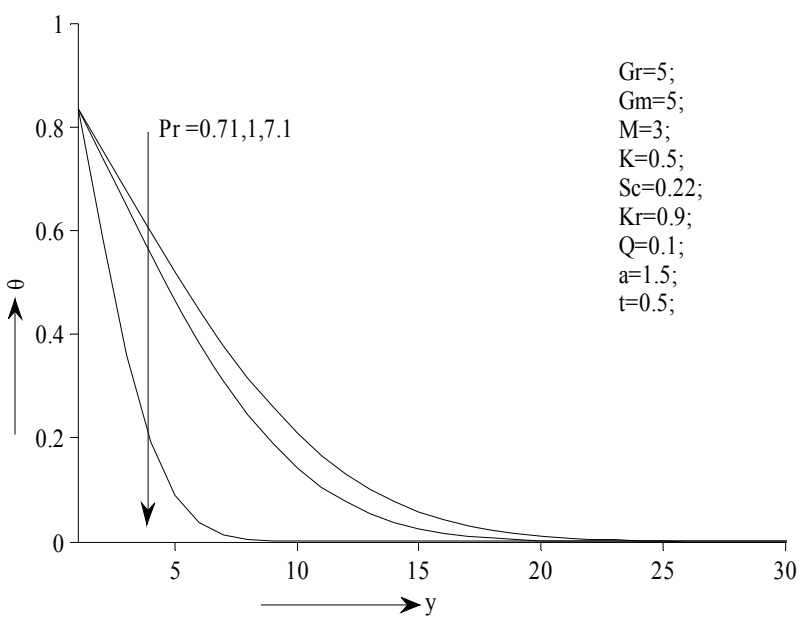

Fig. 5 Effect of Prandtl number (Pr) on temperature

The central reason behind this effect is that the heat absorption causes a decrease in the kinetic energy as well as thermal energy of the fluid. The momentum and thermal boundary layers get thinner in case of heat absorbing fluids. It shows reverse effect in the case of heat generation parameter. Influence of Schmidt number on concentration is shown in
Fig.7, from this figure it is noticed that concentration decreases with an increase in Schmidt number. Because, Schmidt number is a dimensionless number defined as the ratio of momentum diffusivity and mass diffusivity, and is used to characterize fluid flows in which there are simultaneous momentum and mass diffusion convection processes. Therefore, concentration boundary layer decreases with an increase in Schmidt number. From Fig.8, we observe that the concentration(C) decreases as chemical reaction $(\mathrm{Kr})$ increases.

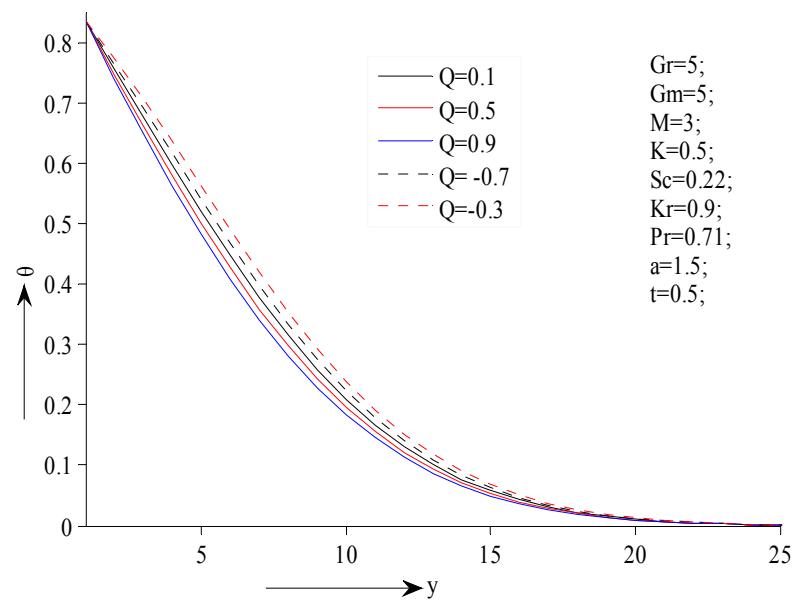

Fig. 6 Effect of Heat absorption/Generation (Q) on temperature

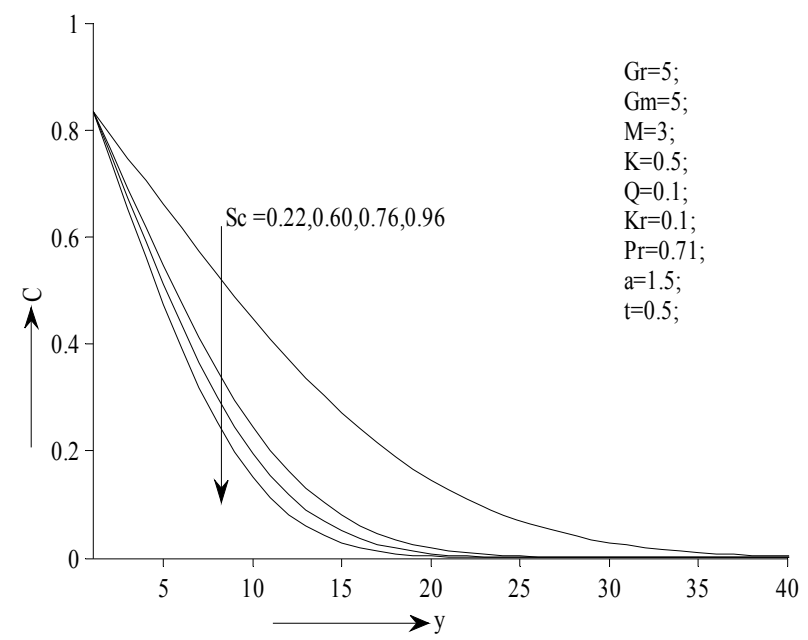

Fig. 7 Effect of Schmidt (Sc) on Concentration

The effects of some of the above parameters on skin friction, Nusselt number and Sherwood number are also analyzed with the help of graphs. The effects of Grashof number (G), modified Grashof number $(\mathrm{Gm})$ and magnetic parameter $(\mathrm{M})$ on skin friction are represented in figures 9-11. From these figures it is noticed that skin friction decreases as an increase in Grashof number, modified Grashof number but skin friction increases as an increase in Magnetic parameter (M). Figures 12 and 13 demonstrate the effect of Prandtl number (Pr) and heat absorption parameter $(\mathrm{Q})$ on Nusselt number $(\mathrm{Nu})$. It is observed that Nusselt number increase as Prandtl number and heat absorption parameter increase. Figures 14 and 15 show the effect of Schmidt number $(\mathrm{Sc})$ and chemical reaction $(\mathrm{Kr})$ on Sherwood number. It is noticed that Sherwood increases as increase in Schmidt number and chemical reaction. 


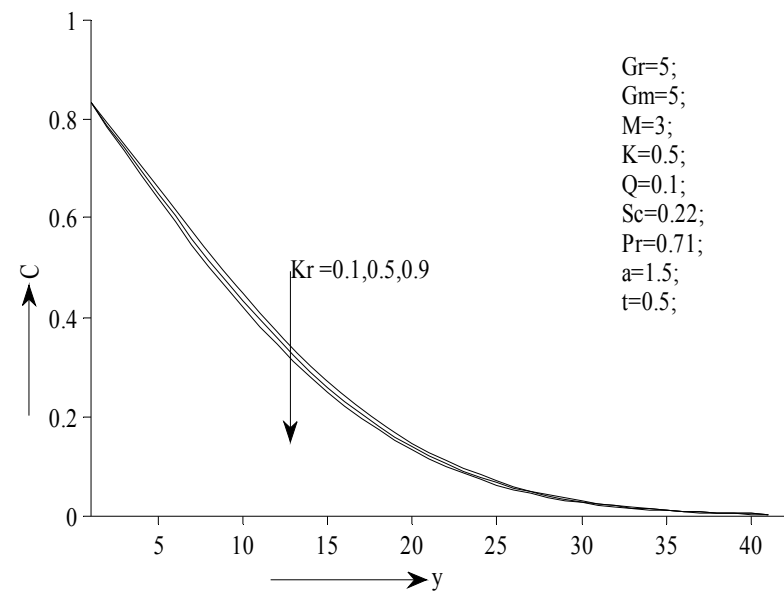

Fig. 8 Effect of Chemical reaction $(\mathrm{Kr})$ on $\mathrm{C}$

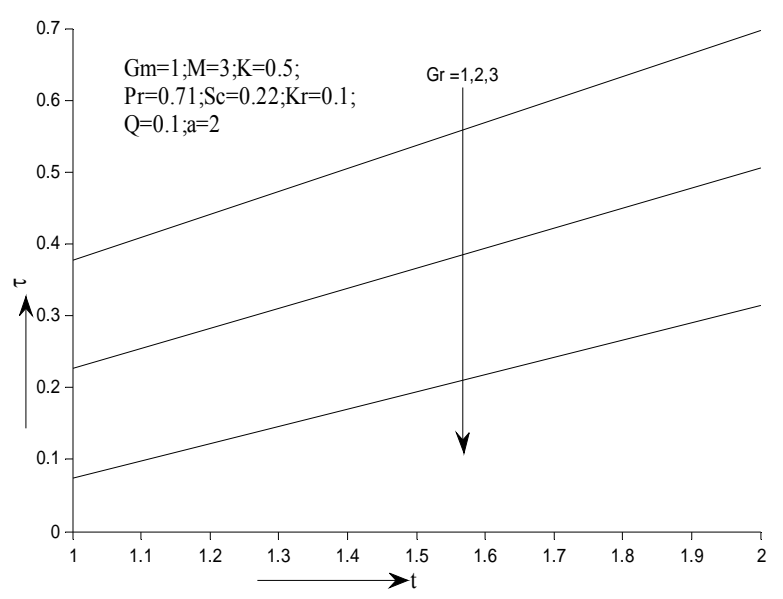

Fig. 9 Effect of Grashof number (Gr) on Skin friction

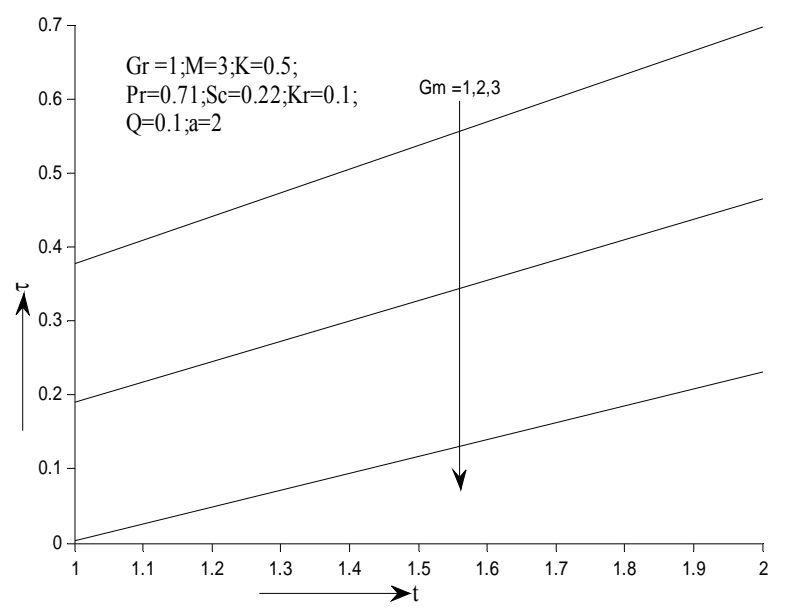

Fig. 10 Effect of modified Grashof number (Gm) on Skin friction

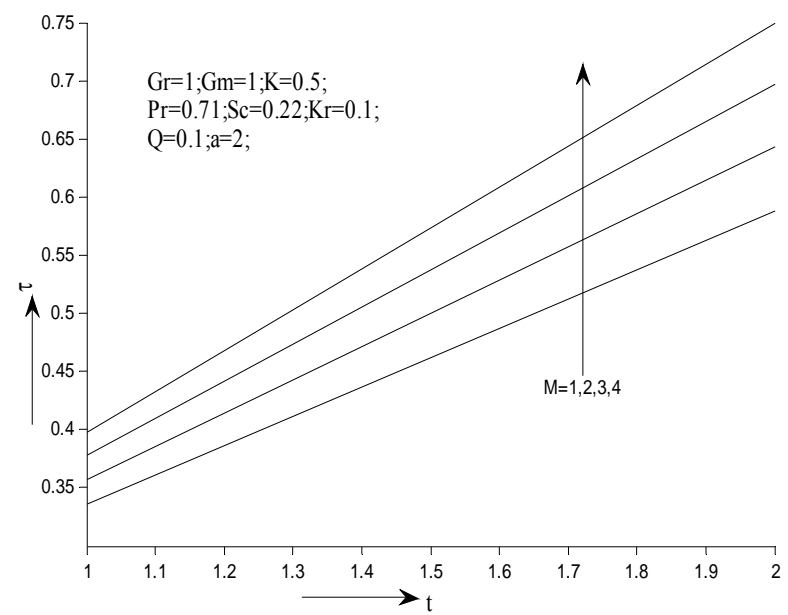

Fig. 11 Effect of Magnetic parameter (M) on Skin friction

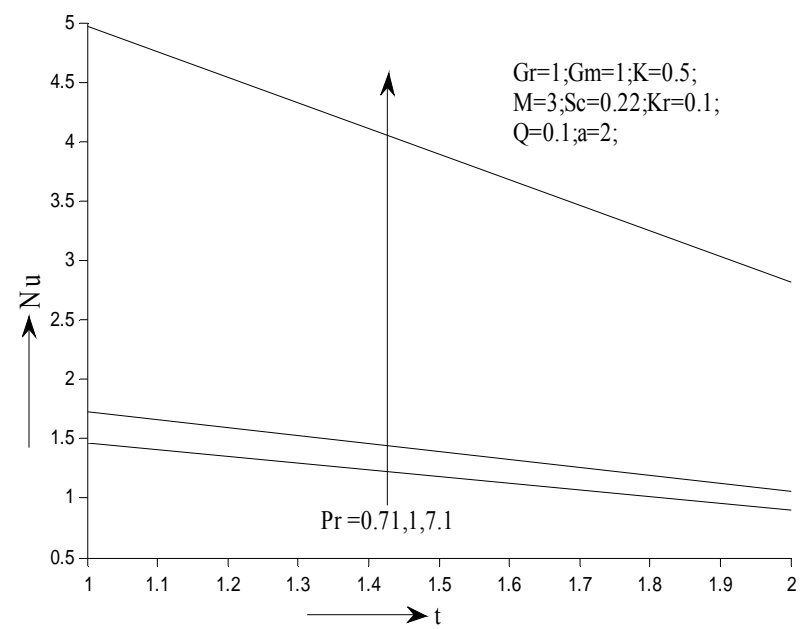

Fig. 12 Effect of Prandtl number (Pr) on Nusselt number

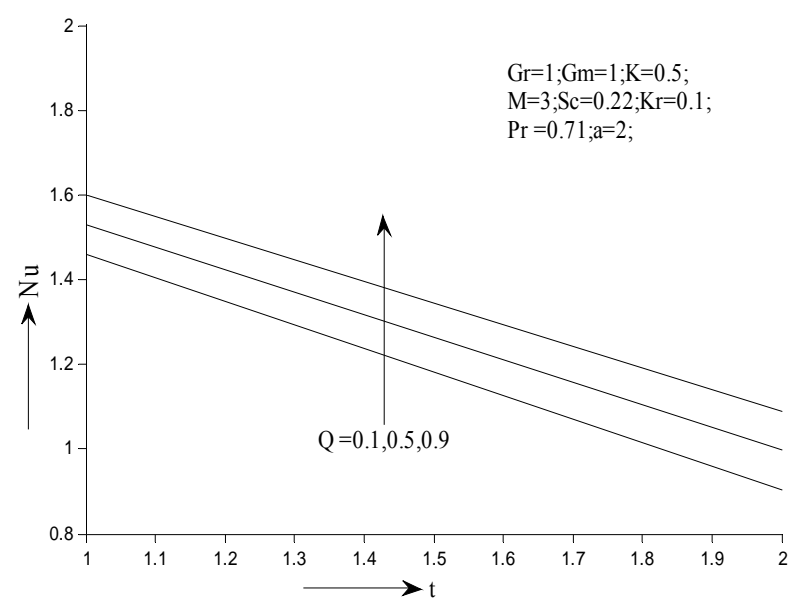

Fig. 13 Effect of heat absorption parameter (Q) on Nusselt number 


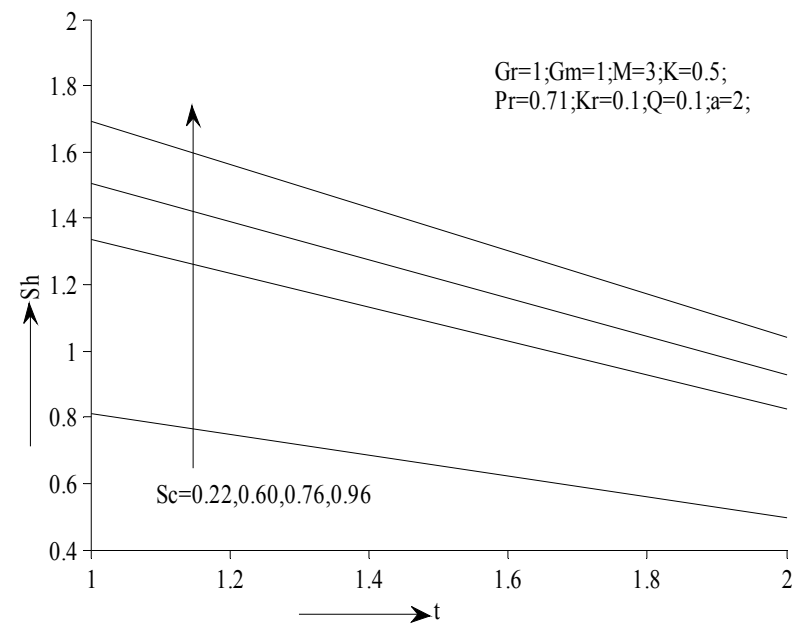

Fig. 14 Effect of Schmidt number (Sc) on Sherwood number

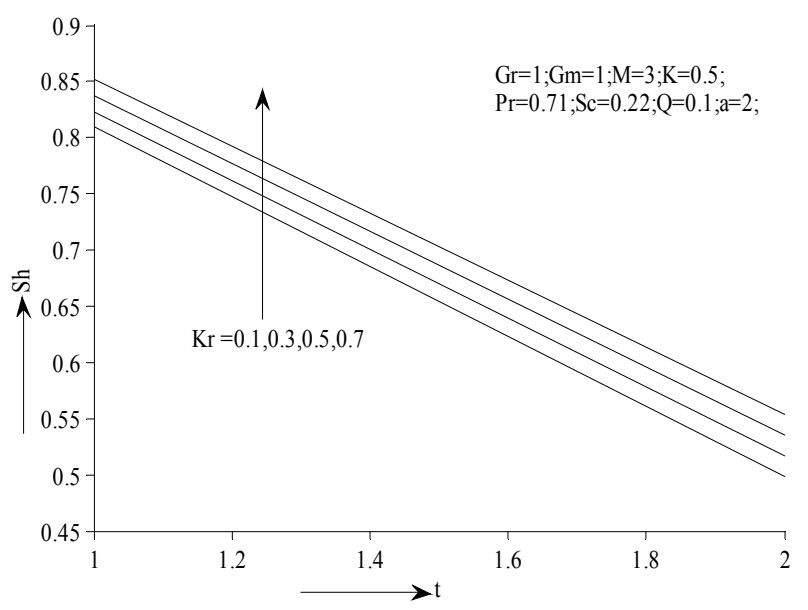

Fig. 15 Effect of Chemical reaction parameter $(\mathrm{Kr})$ on Sherwood

\section{CONCLUSION:}

We investigated the analysis of MHD transient free convection flow of a Newtonian fluid past an infinite vertical porous plate. The governing boundary-layer equations are formulated with appropriate boundary conditions. The governing boundary layer equations are simplified and non-dimensionalized. The dimensionless equations are solved using the Finite difference method. The effects of various physical parameters which are: Grashof number $(\mathrm{Gr})$, modified Grashof number $(\mathrm{Gm})$, magnetic field (M), Schmidt number(Sc), Prandtl number (Pr) and chemical reaction parameter $(\mathrm{Kr})$ are considered on the dimensionless velocity, temperature and concentration. Computations on the variation of local skin friction, Nusselt number and Sherwood number are also discussed through graphs. From the graphs plotted, we discover that:

1) Velocity decreases with an increase in Magnetic field while it increases with increase in Grashof number modified Grashof number, Permeability parameter.

2) Temperature increases with increase in heat absorption and it shows reverse effect in the case of heat generation and Prandtl number.

3) Concentration decreases with increase in Schmidt number and chemical reaction parameter.
4) Local skin friction decreases with increase in Grashof number, modified Grashof number where as it has reverse effect in the case of magnetic parameter.

5) Nusselt number increases with increase in Prandtl number and heat absorption parameter.

6) Sherwood number decreases with increase in Schmidt number and chemical reaction.

\section{REFERENCES}

Anjalidevi, S. P., and Kandasamy, R., 2000, "Effects of a Chemical Reaction Heat and Mass Transfer on MHD Flow Past a Semi-Infinite Plate," Z. Angew.Math.Mech., 80, 697-701. http://dx.doi.org/10.1002/1521-4001(200010)80:10\%3C697::aidzamm697\%3E3.0.co;2-f

Chamkha, A.J., 2003, "MHD Flow of a Uniformly Stretched Vertical Permeable Surface in the Presence of Heat Generation/Absorption and a Chemical Reaction," Int. Commun. Heat Mass Transfer, 30(3), 413422. http://dx.doi.org/10.1016/S0735-1933(03)00059-9

Chamkha, A.J., 2004, "Unsteady MHD Convective Heat and Mass Transfer Past A Semi-infinite Vertical Permeable Moving Plate with Heat Absorption,” Int. J. Eng. Sci., 42, 217-230. http://dx.doi.org/10.1016/S0020-7225(03)00285-4

Cortell, R., 2007, "MHD Flow And Mass Transfer Of An Electrically Conducting Fluid Of Second Grade In A Porous Medium Over A Stretching Sheet With Chemically Reactive Species," Chemical Engineering and Processing, 46(8), 721-728. http://dx.doi.org/10.1016/j.cep.2006.09.008

Hayat, T., Qasim, M., \& Mesloub, S., 2011, "MHD Flow and Heat Transfer over Permeable Stretching Sheet with Slip Conditions," International Journal for Numerical Methods in Fluids, 66(8), 963975.

http://dx.doi.org/10.1002/fld.2294

Hossain, M. A., \& Mandal, A. C., 1985, "Mass Transfer Effects On The Unsteady Hydromagnetic Free Convection Flow Past an Accelerated Vertical Porous Plate," J. Phys. D: Appl. Phys., 18, 63-169. http://dx.doi.org/10.1088/0022-3727/18/7/003

Jha, B.K., 1991, "MHD Free Convection Mass Transform Flow through A Porous Medium," Astrophysics and Space Science, 175(2), 283-289. http://dx.doi.org/10.1007/BF00644290

Kandasamy, R., Muhaimin, I., and Salim, H. , 2010, "Lie Group Analysis for the Effect of Temperature - Dependent Fluid Viscosity with Thermophoresis and Chemical Reaction on MHD Free Convective Heat and Mass Transfer over a Porous Stretching Surface In The Presence Of Heat Source / Sink," Comm. Nonlinear Sci. Num. Simul, 15, P2109-2123.

http://dx.doi.org/10.1016/j.cnsns.2009.09.016

Kandasamy, R., Periasamy, K., and Prabhu, K. K. S., 2005, "Chemical Reaction, Heat And Mass Transfer on MHD Flow over a Vertical Stretching Surface with Heat Source and Thermal Stratification Effects," Int. J. Heat Mass Transfer, 48, pp.4557-4561.

http://dx.doi.org/10.1016/j.ijheatmasstransfer.2005.05.006

Kaprawi, S., 2015, “Analysis of Transient Natural Convection Flow Past an Accelerated Infinite Vertical Plate," International Journal of Engineering Research, 4(2), 47-50.

Khan, W.A., Makinde, O.D., \& Khan, Z.H., 2014, “MHD Boundary Layer Flow of a Nanofluid Containing Gyro Tactic Microorganisms Past a Vertical Plate with Navier Slip," International Journal of Heat and Mass Transfer, 74, 285-291.

http://dx.doi.org/10.1016/j.ijheatmasstransfer.2014.03.026 
Kim, J.Y., 2000, "Unsteady MHD Convective Heat Transfer Past A Semi-infinite Vertical Porous Moving Plate with Variable Suction," Int. J. Eng. Sci., 38, 833-845.

http://dx.doi.org/10.1016/S0020-7225(99)00063-4

Mishra, S.R., Dash, G.C., and Acharya, M., 2013, "Mass and Heat Transfer Effect on MHD Flow of a Visco-elastic Fluid through Porous Medium with Oscillatory Suction and Heat Source," International

Journal of Heat and Mass Transfer, 57(2), 433-438.

http://dx.doi.org/10.1016/j.ijheatmasstransfer.2012.10.053

Muthucumaraswamy, R., and Ganesan, P., 2002, "Natural Convection on a Moving Isothermal Vertical Plate with Chemical Reaction," Journal of Engineering Physics and Thermophysics, 75(1), 51 - 75. http://dx.doi.org/10.1023/A:1014826924926

Muthucumaraswamy, R., Janakiraman, B., 2006, "MHD and Radiation Effects on Moving Isothermal Vertical Plate With Variable Mass Diffusion," Journal of Theoretical and Applied Mechanics, 33, 17-29. http://dx.doi.org/1450-5584/2006/1450-55840601017M

Pal, D., 2013, "Hall Current and MHD Effects on Heat Transfer over an Unsteady Stretching Permeable Surface with Thermal Radiation," Computers and Mathematics with Applications, 66, 1161-1180. http://dx.doi.org/10.1016/j.camwa.2013.07.010

Pal, D., Chatterjee, S. , 2010, "Heat and Mass Transfer In MHD NonDarcian Flow of a Micro Polar Fluid over a Stretching Sheet Embedded in a Porous Media with Non-Uniform Heat Source and Thermal Radiation," Communications in Nonlinear Science and Numerical Simulation, 15, 1843-1857.

http://dx.doi.org/10.1016/j.cnsns.2009.07.024

Patil, PM., Roy, S., and Pop, I. , 2013, “Chemical Reaction Effects on Unsteady Mixed Convection Boundary Layer Flow Past a Permeable Slender Vertical Cylinder Due To A Nonlinearly Stretching Velocity," Chemical Engineering Communications, 200 (3), 398-417.

http://dx.doi.org/10.1080/00986445.2012.712578

Prakash, J., Bhanumathi, D., Vijaya Kumar, A. G., and Varma, S. V. K., 2013, "Diffusion- Thermo And Radiation Effects On Unsteady MHD Flow Through Porous Medium Past An Impulsively Started Infinite Vertical Plate With Variable Temperature And Mass Diffusion," Trans. Porous. Med., 96, 135-151.

http://dx.doi.org/10.1007/S11242-012-0078-x

Raptis, A., and Perdikis, C., 2006, "Viscous Flow over a Non-linearly Stretching Sheet In The Presence Of a Chemical Reaction and Magnetic Field," International Journal of Non-Linear Mechanics, 41(4), pp.527529.

http://dx.doi.org/10.1016/i.ijnonlinmec.2005.12.003

Seini, Y.I., and Makinde, O.D., 2014, "Boundary Layer Flow Near Stagnation-points on a Vertical Surface with Slip in the Presence of Transverse Magnetic Field," International Journal of Numerical Methods for Heat and Fluid Flow, 24(3), 643-653.

http://dx.doi.org/10.1108/hff-04-2012-0094

Seth, G. S., and Ansari, Md. S., 2010, "MHD Natural Convection Flow Past an Impulsively Moving Vertical Plate with Ramped Wall
Temperature in the Presence of Thermal Diffusion with Heat Absorption,” Int. J. Appl. Mech. Eng., 15(1), 199-215.

Seth, G.S. Ansari, Md. S., and Nandkeolyar, R., 2011, "MHD Natural Convection Flow with Radiative Heat Transfer Past an Impulsively Moving Plate with Ramped Wall Temperature," Heat Mass Transfer, 47, 551-561. http://dx.doi.org/10.1007/S00231-010-0740-1

Seth, G. S., Hussain, S. M., and Sarkar, S., 2014a, "Hydromagnetic Natural Convection Flow With Radiative Heat Transfer Past an Accelerated Moving Vertical Plate With Ramped Temperature Through A Porous Medium,” J. Porous Media, 17(1), 67-79.

http://dx.doi.org/10.1615/jpormedia.v17.i1.50

Seth, G. S., Hussain, S. M., and Sarkar, S., 2014b, "Effects of Hall Current and Rotation On Unsteady MHD Natural Convection Flow with Heat and Mass Transfer Past an Impulsively Moving Vertical Plate in the Presence of Radiation and Chemical Reaction," Bulg. Chem. Comm., 46(4), 704-718.

Seth, G.S., Nandkeolyar, R., and Ansari, Md. S., 2013, "Effects of Thermal Radiation and Rotation on Unsteady Hydromagnetic Free Convection Flow Past an Impulsively Moving Vertical Plate with Ramped Temperature in a Porous Medium," J. Appl. Fluid Mech., 6(1), 27-38.

Seth, G. S., Sharma, R., \& Hussain S. M., 2014c, "Hall Effects on Unsteady MHD Natural Convection Flow of a Heat Absorbing Fluid Past an Accelerated Moving Vertical Plate with Ramped Temperature," Emirates J. Eng. Res., 19(2), 19-32.

Singh, A.K., 2001, "MHD Free Convection and Mass Transfer Flow with Heat Source and Thermal Diffusion," Journal of Energy Heat and Mass Transfer, 23, 167-178.

Sonth, R. M., Khan, S. K., Abel, M. S. , and Prasad, K. V. , 2002, "Heat and Mass Transfer in a Visco-elastic Fluid Flow over an Accelerating Surface With Heat Source/sink And Viscous Dissipation," Heat and Mass Transfer, 38(3), 213-220.

http://dx.doi.org/10.1007/S002310100271

Takhar, H. S, Chamkha, A. J and Nath, G., 2000, "Flow and Mass Transfer on a Stretching Sheet with a Magnetic Field and Chemically Reactive Species,” Int. J. Eng. Sce. 38, 13-16.

http://dx.doi.org/10.1016/S0020-7225(99)00079-8

Umamaheswar, M., Varma, S. V. K., and Raju, M. C., 2013, "Unsteady MHD Free Convective Visco-elastic Fluid Flow Bounded by an Infinite Inclined Porous Plate in the Presence of Heat Source, Viscous Dissipation and Ohmic Heating," International Journal of Advanced Science and Technology, 61, 39-52.

http://dx.doi.org/10.14257/ijast.2013.61.05

Vajravelu, K., Prasad, K.V., and Chiu-On Ng, 2013, "Unsteady Convective Boundary Layer Flow of a Viscous Fluid at a Vertical Surface with Variable Fluid Properties," Non-linear Analysis: Real World Applications, 14, 455-464. http://dx.doi.org/10.1016/j.nonrwa.2012.07.008 